\title{
Optimizing Submarine Berthing with a Persistence Incentive
}

\author{
Gerald G. Brown, Kelly J. Cormican, Siriphong Lawphongpanich, \\ Daniel B. Widdis \\ Department of Operations Research, Naval Postgraduate School, Monterey, \\ California 93943
}

Received October 1995; revised November 1996; accepted 3 December 1996

"Where lies the final harbor, whence we unmoor no more." $\quad$ Melville, Moby Dick

\begin{abstract}
Submarine berthing plans reserve mooring locations for inbound U.S. Navy nuclear submarines prior to their port entrance. Once in port, submarines may be shifted to different berthing locations to allow them to better receive services they require or to make way for other shifted vessels. However, submarine berth shifting is expensive, labor intensive, and potentially hazardous. This article presents an optimization model for submarine berth planning and demonstrates it with Naval Submarine Base, San Diego. After a berthing plan has been approved and published, changed requests for services, delays, and early arrival of inbound submarines are routine events, requiring frequent revisions. To encourage trust in the planning process, the effect on the solution of revisions in the input is kept small by incorporating a persistence incentive in the optimization model. (C) 1997 John Wiley \& Sons, Inc. Naval Research Logistics 44: 301-318, 1997.
\end{abstract}

\section{INTRODUCTION}

Although the Cold War has ended, United States Navy submarines remain very capable and effective ships of war: A smaller number of submarines operated from fewer submarine bases will continue to play a significant role in national defense. The wise use of time and resources while submarines are in port will improve the state of readiness of a smaller fleet.

While in port, a submarine completes preventive and corrective maintenance, replenishes stores, and conducts training and certification tests to maintain high material and personnel readiness. Ideally, a submarine in port should devote its time exclusively to these activities. However, submarines frequently spend time shifting berths. Some shifts are necessary and some are not. Services such as ordnance loading and the use of special maintenance equipment require that a submarine be moored at a specific location. During periodic maintenance upkeep, personnel from a submarine tender assist the submarine crew, and berthing near the tender is preferable. During training, inspection, and other periods, it is desirable to berth closer to shore, near squadron offices and training facilities. When conditions permit,

Correspondence to: S. Lawphongpanich.

(C) 1997 by John Wiley \& Sons, Inc.

CCC 0894-069X/97/040301-18 
it is traditional for some submarines, such as those returning from extended deployment, to have priority berthing pierside.

A submarine berth shift is both hazardous and disruptive. Submarines have limited maneuverability during the shift and handling lines such as mooring and tow lines is risky. Preferably, berth shifts should be conducted during daylight hours. During a berth shift, submarines are unable to conduct most maintenance and additional delay must be planned when setting deployment dates. To support the berth shift, on-board equipment must also be shut down and restarted, thereby further reducing equipment life.

Berth shifts are also costly. A SSN688 Los Angeles submarine cost $\$ 0.80$ billion in 1990 ( $\$ 0.93$ billion in 1995) and an Ohio Class Trident Submarine cost $\$ 1.28$ billion in 1991 ( $\$ 1.44$ billion in 1995) [11]. Ignoring the considerable additional costs of weapons, crew, and consumables, a conservative cost estimate for one nuclear submarine is easily $\$ 1$ billion. Considering this cost along with the costs of port personnel, equipment, and lost opportunity, berth shifts are not cheap.

An optimal submarine berthing plan would consider all feasible berthing arrangements for a practical time horizon and present an optimal arrangement with respect to physical constraints, procedural requirements, and desirability of mooring locations. However, a human scheduler cannot be expected to consider all these details and their interactions over many days of operations. A computerized optimization model would therefore be beneficial to assist the scheduler in assigning submarines to berths that provide the required services, meet berthing constraints, and minimize costly berth shifts.

Once a berthing plan has been approved, changes are inevitable. Changed requests for services, delays, and early arrival of inbound submarines are routine events and they require frequent revisions to the approved plan. An optimization model that only minimizes the costly berth shifts is not appropriate in this situation, for it can be expected to amplify minor modifications in service requests into wholesale revisions in the approved berthing plan. Revisions to the plan and the disruptions they bring must be controlled to encourage trust in the planning process. There are a number of techniques for moderating the severity of revisions ( see, e.g., [3]). One such technique requires penalties when there is a difference between the published and revised plans, thereby providing an incentive to adhere to the published plan.

This article presents an optimization model for submarine berth planning. Section 2 describes Naval Submarine Base, San Diego, and presents the guidelines and physical constraints and objectives that govern berthing there. Section 3 presents an optimization model formulation, and a specimen berthing plan is presented in Section 4. Section 5 describes a key modification to deal with changes in requests for services after a schedule has already been promulgated. Finally, Section 6 discusses benefits of computerized models in submarine berthing.

\section{NAVAL SUBMARINE BASE, SAN DIEGO}

Naval Submarine Base, San Diego, California, berths submarines, tenders, and floating dry docks at three piers. A schematic of the base and a sample berthing configuration are shown in Figure 1. Submarine types typically berthed in San Diego are the SSN-637 (STURGEON), SSN-688 (LOS ANGELES), and SSBN-726 (OHIO-TRIDENT) classes. The water depth at Naval Submarine Base, San Diego, normally accommodates all types of submarines at all berthing locations.

Current berth planning is routinely accomplished by a weekly meeting of the Operations 


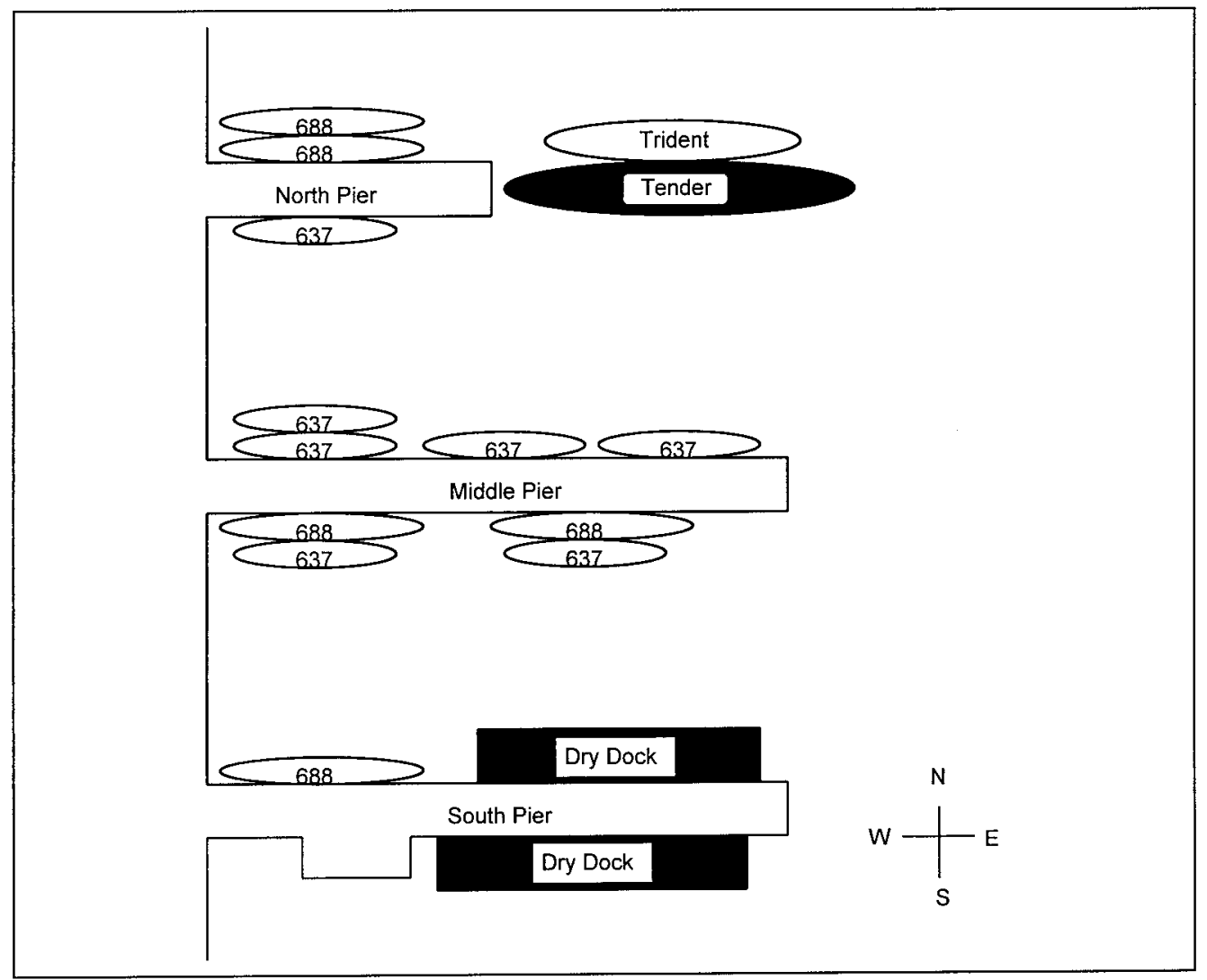

Figure 1. Naval Submarine Base, San Diego. Three piers are used to berth SSBN-726 Trident, SSN-688 Los Angeles, and SSN-637 Sturgeon submarines. Submarines may berth in nests - groups of two or more occupying a single pier berth position - and a tender may be used as a pier extension. Shore services and squadron offices are at the left (west).

Officer, Selected Restricted Availability coordinator, and Weapons Officer as representatives of Submarine Group Five; the Operations, Weapons, and Material Officers as representatives of Squadrons Three and Eleven; the tender Operations Officer; and base Port Services representative. These persons all voice the respective berthing desires of each organization and submarine. The results from this meeting are weighed by the scheduler, who constructs a berthing plan for the following week.

Even after plan approval, frequent revisions are necessary. Changes in material conditions of inbound or already berthed vessels can force one or more submarines to berth in less-thanideal locations. Occasionally, the planners at the berth scheduling meeting may inadvertently overlook some of the fine details pertinent to the collective berthing of all submarines. The consequence is additional berth shifts, resulting in lost time and money.

\subsection{Berthing Considerations}

When berthing assignments are being determined, several aspects must be considered. Some of these factors result in actual restrictions of possible berthing arrangements [5]. For example: 
1. Because of shore power limitations, a maximum of three submarines may berth alongside the tender at any given time.

2. A submarine berthing outboard another must be of equal length or shorter than the inboard nested submarine.

Other considerations influence berthing but are treated not as restrictions but rather as objectives by the scheduler. For example:

1. Minimize the number of costly (in many aspects) berth shifts.

2. Submarines requiring specific services should be berthed in a location that facilitates service accomplishment.

3. Submarines requesting no other submarines outboard should be berthed appropriately.

4. Give priority, whenever possible, to certain submarines, such as those returning from deployment or conducting a change-of-command ceremony.

5. Preferentially assign berths pierside versus nested outboard another submarine, all other factors being equal.

6. Preferentially assign berths closer to the shoreline near the shore facilities versus at the end of the pier, all other factors being equal.

Other berthing guidelines considered at Naval Submarine Base, San Diego, are presented in the Appendix.

\section{SUBMARINE BERTHING MODEL}

We seek an optimal berthing plan at a daily level of detail for all submarines scheduled to be in port during a prospective planning horizon of 1-2 weeks. The berthing plan for the first week is directive. A second week may be included for informative purposes and extends model vision. The berthing requirements and objectives are defined mathematically below.

The situation calls for a set of discrete ship-to-berth assignments, with limitations on feasible assignments. These limitations are easily expressed as linear functions of ship-toberth assignment variables. This suggests a linear integer program that encompasses prior surface ship berthing modeling experience by Thurman [12], Brown, Lawphongpanich, and Thurman [4], Widdis [13], and Cormican [6].

\subsection{Formulation as a Linear Integer Program}

\section{Indices}

$s$ individual submarines,

$\sigma$ alternate index for $s$,

$p \quad$ piers (e.g., $p=\mathrm{N} 1, \mathrm{~N} 2, \mathrm{M} 1, \mathrm{M} 2$, or $\mathrm{S}$ ),

$b$ berths (at each pier),

$n$ nesting position (at each berth),

$t$ days, where $t=0,1,2, \cdots$ and $t=0$ indicates the current day, and

$q$ types of requests while in port. 


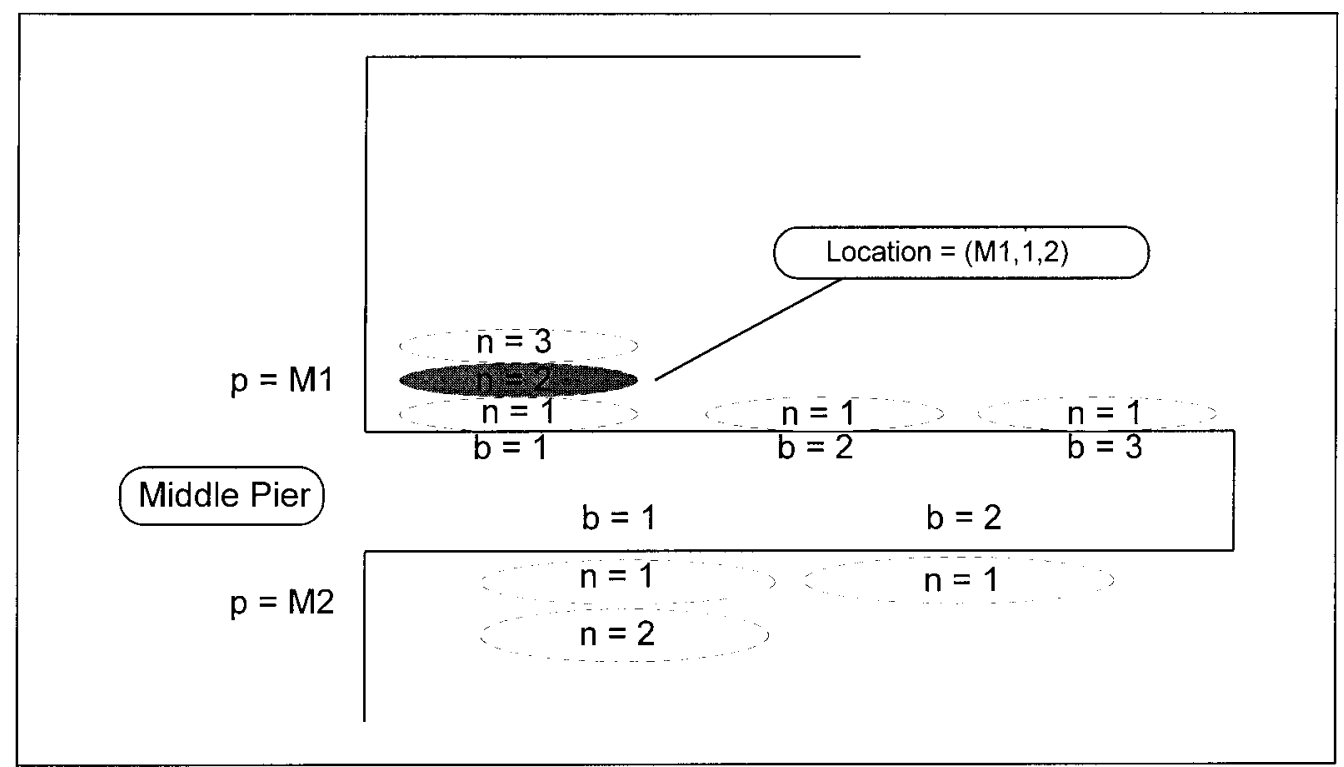

Figure 2. Berthing locations. The middle pier at Naval Submarine Station, San Diego, has two pier sides $(\mathrm{M} 1=$ North and M2 $=$ South $)$, each with several berths. In addition, several submarines may nest at a single berth. The shaded area shows pier M1, berth 1, nesting position 2 .

Indices $p, b$, and $n$ indicate berthing locations, illustrated in Figure 2 for the middle pier of the Naval Submarine Station, San Diego. In Figure 2, $p=$ M1 represents the north side of the middle pier, whereas $p=\mathrm{M} 2$ represents the south side. Similar meanings apply to $p=\mathrm{N} 1$ and N2. For the south pier, submarines can only moor on one side, and the pier is represented with a single letter $\mathrm{S}$.

For pier $p$, index $b$ ranges from 1 to $B_{p}$ to allow for different numbers of berthing positions at different piers. At San Diego, the north and south piers have only one berthing position, and the middle pier has three. When in port, the tender is treated as a second berthing position at the north pier. Similarly, index $n$ ranges from 1 to $N_{b}$ to allow for different numbers of nesting positions at different berths.

The service requests indexed by $q$ typically limit the choice of berthing locations for a given submarine. A submarine requiring weapon loading or nuclear work must be moored near certain facilities or at locations that have the necessary equipment. Sometimes, a submarine may request to have no other submarines berthed outboard from it (NOB) or simply to be pierside or tenderside. To indicate the allowable berthing locations for each request, we define the following index set.

\section{Index Set}

$(p, b, n) \in \mathrm{ALOC}_{q}=$ the set of all legitimate berthing locations $(p, b, n)$ where service $q$ can be performed.

Note that $\mathrm{ALOC}_{q}$ may consist of only one berthing location, thus providing a mechanism to express manual preassignments by the scheduler. 


\section{Given and Derived Data}

$\mathrm{BN}_{s p b n t}$ benefit for berthing submarine $s$ at pier $p$, berth $b$, nesting position $n$ on day $t$.

$\mathrm{QP}_{s q} \quad$ penalty for failing to perform service $q$ on submarine $s$.

$\mathrm{SP} \quad$ penalty for performing a berth shift.

$\mathrm{IP}_{s t} \quad=1$ if submarine $s$ requires a berth on day $t$,

$=0$ otherwise.

$\mathrm{LS}_{s} \quad$ Length of submarine $s$.

$\mathrm{LP}_{p} \quad$ Length of pier $p$.

$\mathrm{T}_{t}=1$ if the tender is in port on day $t$,

$=0$ otherwise.

$\mathrm{SR}_{q s t}=1$ if service $q$ is requested by submarine $s$ on day $t$,

$=0$ otherwise.

In the data above, the value of $\mathrm{BN}_{\text {spbnt }}$ affects the level of satisfaction of the overall plan by rewarding a berthing assignment considered to be beneficial. A port scheduler can manipulate the value of $\mathrm{BN}_{s p b n t}$ to achieve the desired berthing assignments. In general, it is better to moor submarines pierside or tenderside, closer to the shoreline and to have no other submarine outboard. It is also desirable to satisfy the requests that are closer to the present because future requests are less certain and more likely to change. Finally, the value of $\mathrm{BN}_{s p b n t}$ can also reflect the priority for submarines returning from extended deployment.

\section{Decision Variables}

$$
\begin{aligned}
X_{s p b n t}= & 1 \text { assigns submarine } s \text { to pier } p, \text { berth } b \text {, and nesting position } n \text { on day } \\
& t, \\
= & 0 \text { otherwise. } \\
Z_{p b n t}= & 1 \text { if there is an assignment change at location }(p, b, n) \text { between days } \\
& t-1 \text { and } t, \\
= & 0 \text { otherwise. } \\
F_{q s t}= & 1 \text { indicates a failure to provide service } q \text { for submarine } s \text { on day } t, \\
= & 0 \text { otherwise. }
\end{aligned}
$$

To simplify our presentation, it is assumed in the following formulation that only legitimate and meaningful combinations of $(p, b, n, t)$ and $(s, p, b, n, t)$ are used. For example, combinations $(\mathrm{N} 1,3,2, t)$ for any value of $t$ is illegitimate for the Naval Submarine Base, San Diego (see Figure 1) and combinations $(s, p, b, n, t)$ for which submarine $s$ is not in port on day $t\left(\mathrm{IP}_{s t}=0\right)$ are not meaningful. Because the second berthing position at the north pier represents the tender, combinations $(\mathrm{N} 1,2, n, t)$ and $(\mathrm{N} 2,2, n, t)$ are meaningful for any value $n$ only when the tender is in port $\left(\mathrm{T}_{t}=1\right)$.

The variables $Z_{p b n t}$ only account for berth shifts between two consecutive days. Further refinement in accounting for berth shifts would require a considerable number of additional constraints and variables. When submarine $s$ changes its location between days $(t-1)$ and $t$, shifting activities occur both at the old and new locations. $Z_{p b n t}$ can be used to indicate activities at only one of the locations. Activities at the other location would require a new set of variables. In addition, any temporary shifting of outboard or nesting submarines to allow a submarine to be moved from one location to another must be also be accounted 
for with additional sets of variables and constraints (see [13]). Similarly, accounting for any saving resulting from simultaneous shifts of nesting submarines would also require additional variables and constraints. Instead of adding these variables and constraints and making the resulting problem too large to be practical, the following formulation provides a berthing plan that only accounts for changes in berthing assignments between 2 consecutive days.

\section{Formulation}

Maximize

$$
\sum_{(s, p, b, n, t)} \mathrm{BN}_{s p b n t} X_{s p b n t}-\sum_{(q, s, t)} \mathrm{QP}_{s q} F_{q s t}-\mathrm{SP} \sum_{(p, b, n, t)} Z_{p b n t},
$$

subject to

$$
\begin{array}{ll}
\sum_{(p, b, n)} X_{s p b n t}=\mathrm{IP}_{s t}, & \forall s, t \geq 1, \\
\sum_{s} X_{s p b n t} \leq 1, & \forall p, b, n, t \geq 1, \\
\sum_{s} \mathrm{LS}_{s} X_{s p b n t}-\sum_{s} \mathrm{LS}_{s} X_{s p b(n+1) t} \geq 0, & \forall p, b, n<N_{b}, t \geq 1, \\
\sum_{(s, b)} \mathrm{LS}_{s} X_{s p b 1 t} \leq \mathrm{LP}_{p}, & \forall p \in\{\mathrm{M} 1, \mathrm{M} 2\}, t \geq 1, \\
\sum_{s} \sum_{n=1}^{2} \sum_{p \in\{\mathrm{N} 1, \mathrm{~N} 2\}} X_{s p 2 n t} \leq 3, & \forall t: T_{t}=1, \\
\mathrm{SR}_{(\mathrm{NOB}) s t} X_{s p b n t}+\sum_{\sigma} X_{\sigma p b(n+1) t}-F_{(\mathrm{NOB}) s t} \leq 1, & \forall s, p, b, n<N_{b}, t \geq 1, \\
\quad \sum_{(p, b, n) \in \mathrm{ALOC}_{q}} \mathrm{SR}_{q s t} X_{s p b n t}+F_{q s t} \geq 1, & \forall s, q \neq \mathrm{NOB}, t \geq 1, \\
X_{s p b n t}-X_{s p b n(t-1)}-Z_{p b n t} \leq 0, & \forall s, p, b, n, t \geq 1, \\
X_{s p b n t} \in\{0,1\}, & \forall s, p, b, n, t, \\
Z_{p b n t} \in[0,1], & \forall p, b, n, t, \\
F_{q s t} \in[0,1], & \forall q, s, t .
\end{array}
$$

The objective function expresses the total benefit for berthing submarines less penalties for berth shifts and for not providing requested services. Constraints (1) require each submarine to occupy exactly one berth each day while in port, and constraints (2) allow only one submarine per berthing location. Constraints (3) allow submarines to berth outboard only when they are no longer than another submarine already occupying an inboard nesting position. Constraints (4) ensure that the combined length of moored submarines do not extend beyond the length of the pier. For Naval Submarine Base, San Diego, constraints (4) only apply to the middle pier. Constraints (5) allow up to three submarines to moor outboard the tender only when it is in port. Constraints (6) restrict any submarine from 
berthing in a nesting position outboard submarines precluding such. Constraints (7) determine whether submarines are able to receive their requested services. Constraints (8) induce initial berthing or deduce berth shifting by determining if a submarine occupies a berth that it did not occupy the previous day. This approach of accounting for berth shifts does not capture berth shifts due to submarines departing from port. However, because departure is an unavoidable event, the penalty due to its associated berth shift can be considered as a constant term in the objective function. (If it is desired to capture all berth shifts, a fictitious pier called AT-SEA and a service request called DEPARTURE can be added to the model, with the restriction that all departed submarines must be berthed at pier AT-SEA.) Conditions (9) restrict berth assignments to be binary, whereas (10) and (11) allow the berth shift and service-failure variables to vary continuously between 0 and 1 . However, these latter continuous variables will intrinsically take on values of 0 or 1 because they are functions of binary data and variables via constraints $(6)-(8)$.

\section{IMPLEMENTATION}

The submarine berthing problem is implemented with the general algebraic modeling system or GAMS (e.g., [1]). To facilitate modifications and to suggest a graphical user interface (GUI) with GAMS, problem data are stored in a spreadsheet, EXCEL [9].

\section{Input Data}

We construct a submarine berthing problem for a typical 7-day period at San Diego, a problem with 10 SSN637s, 6 SSN688s, and one Trident. The initial locations of submarines are expressed via an EXCEL worksheet (Table 1) and displayed graphically in Figure 3. As an example, the $\times$ in the first row of the first column indicates that SSN637-1 is initially located at $(\mathrm{N} 1,1,1)$ which corresponds to the first nesting position at the first berth on the north side of the north pier. To generate the necessary input file for GAMS, the worksheet is saved as a flat file in EXCEL [10, p. 152].

Similarly, the in-port schedule and service requests for the next 7 days are stored in a worksheet displayed in Table 2. Typically, there is a correspondence between each service request and the type of berthing requirement: The letter in each cell indicates the type of berthing requirement corresponding to each request. For the example, there are 7 types of berthing requirements:

$\mathrm{I}=$ in port with no special berthing requested,

$\mathrm{P}=$ pierside berthing,

$\mathrm{N}=$ no outboard berthing,

$\mathrm{S}=$ south pier berthing,

$\mathrm{T}=$ tenderside berthing,

$\mathrm{E}=$ either south pier or tenderside berthing, and

$\mathrm{W}=$ berthing at weapon loading location.

Blank cells indicate that submarines are not in port.

The following values for shifting penalties, service failures, and benefits generate practical berthing plans at San Diego for our example: $\mathrm{SP}=10, \mathrm{QP}_{s q}=20$ for all $s$ and $q$ and 


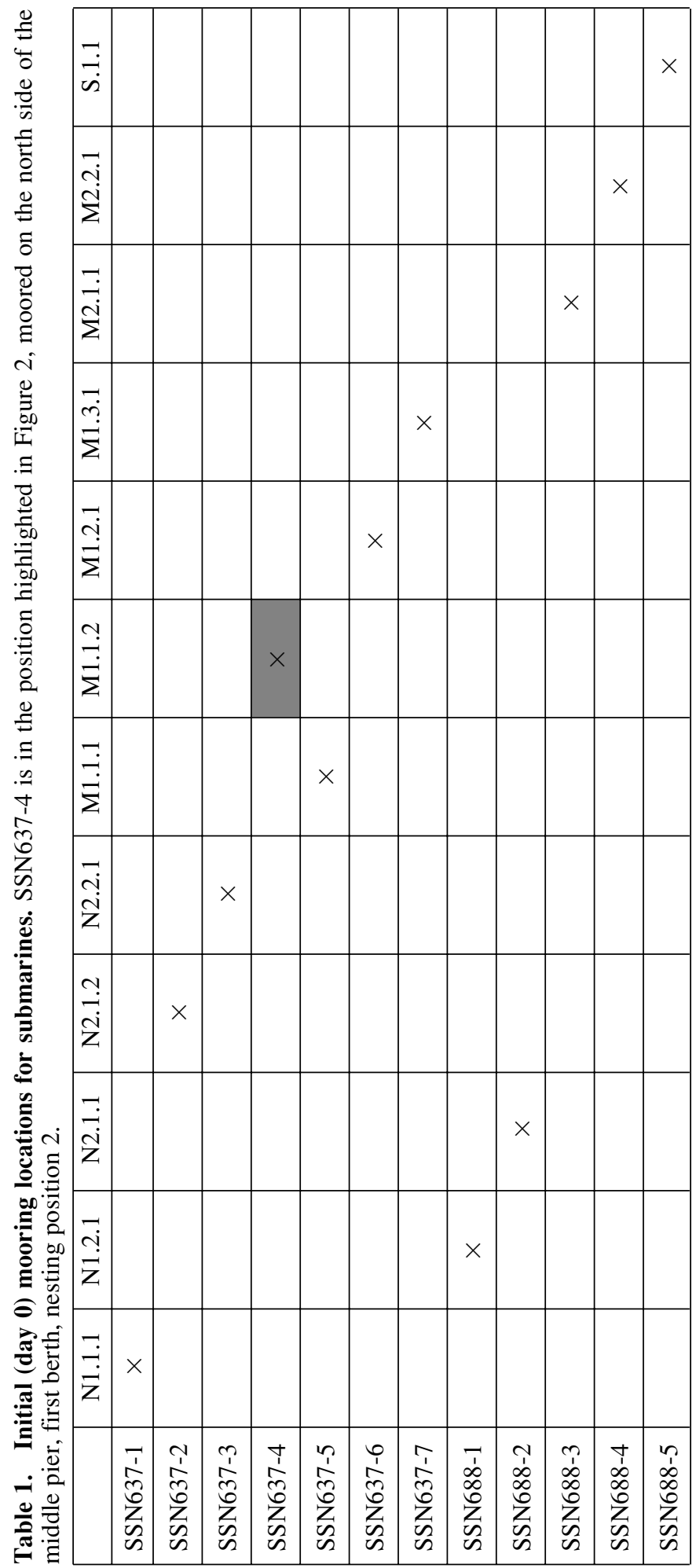




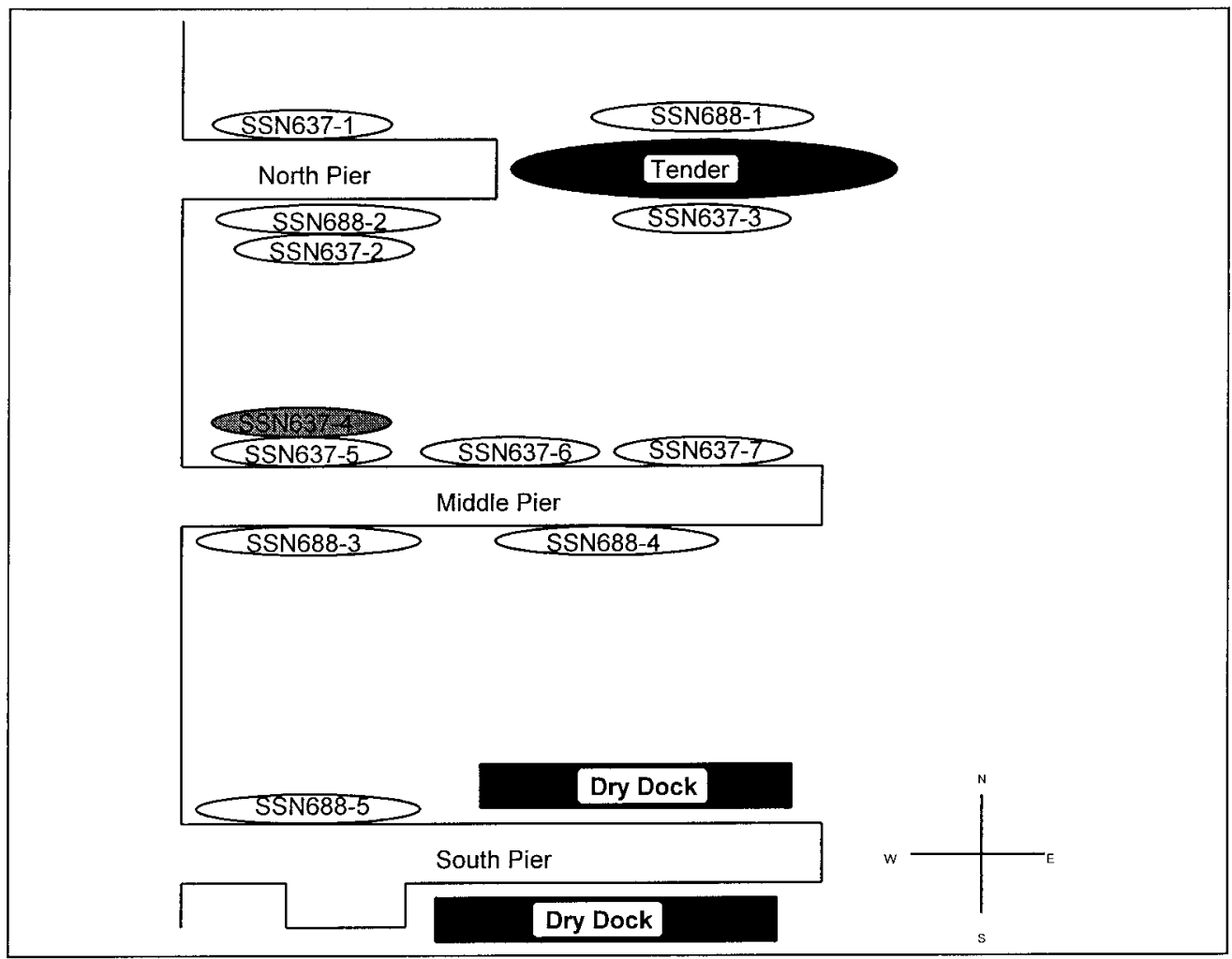

Figure 3. Initial positions of submarines (Day 0). SSN637-4, highlighted in Table 2, is moored at the north side of the middle pier, first berth, nesting position 2 .

$$
\mathrm{BN}_{s p b n t}=(4-n)+(3-b) .
$$

This provides more benefit to submarines berthing closer to shore and at pierside or tenderside locations.

\section{Solving the Problem}

Using the above input data and modifications, GAMS takes 4 CPU seconds on an IBM RS/6000 590H workstation to generate the model containing 2,165 binary variables, 2,528 continuous variables, and 2,711 constraints. Then CPLEX [7] takes another 3 min to obtain an integer solution within $2 \%$ of optimality. Finally, GAMS requires less than $1 \mathrm{~s}$ to generate an output, part of which is shown in Figure 4.

Figure 4 completely specifies daily submarine movements. From Day 0 to Day 1, SSN6377 and SSN637-4 leave the base and SSN688-1 shifts from a tenderside position to a nesting position outside SSN688-3 at the south side of the middle pier. On Day 2, the Trident and SSN637-10 arrive at the base for the first time and SSN637-7 returns after having just left the base the previous day. The Trident berths tenderside, a position previously vacated by SSN688-1. For the other two submarines, SSN637-7 is pierside at berth 3 of the middle pier, and SSN637-10 nests outboard of SSN637-1 at the north pier. Submarine movements 
Table 2. In-port schedule for the example problem. Planning days proceed left to right. SSN637-4 leaves Naval Submarine Station, San Diego, on Day 1 and returns on Day 3. While in port from Day 3 to Day 7, it requires a weapon loading location on Day 6. From the last row, the tender is also inport providing more berthing locations for the north pier during the first 4 days.

\begin{tabular}{|c|c|c|c|c|c|c|c|}
\hline & D1 & D2 & D3 & D4 & D5 & D6 & D7 \\
\hline SSN637-1 & I & I & I & I & I & I & D \\
\hline SSN637-2 & I & I & I & I & I & I & $\mathrm{P}$ \\
\hline SSN637-3 & $\mathrm{T}$ & $\mathrm{T}$ & $\mathrm{T}$ & $\mathrm{T}$ & D & & \\
\hline SSN637-4 & $\mathrm{D}$ & & I & I & I & W & I \\
\hline SSN637-5 & I & I & I & I & I & I & D \\
\hline SSN637-6 & I & I & I & I & I & $\mathrm{N}$ & $\mathrm{N}$ \\
\hline SSN637-7 & & $\mathrm{P}$ & $\mathrm{P}$ & $P$ & D & & \\
\hline SSN637-8 & & & & I & I & $\mathrm{P}$ & $\mathrm{P}$ \\
\hline SSN637-9 & & & $\mathrm{N}$ & $\mathrm{N}$ & $\mathrm{N}$ & $\mathrm{N}$ & D \\
\hline SSN637-10 & & I & I & I & D & & \\
\hline SSN688-1 & I & I & I & I & I & I & D \\
\hline SSN688-2 & I & I & I & I & I & I & I \\
\hline SSN688-3 & I & I & I & I & I & I & D \\
\hline SSN688-4 & I & I & I & I & I & I & I \\
\hline SSN688-5 & S & S & S & S & I & I & I \\
\hline SSN688-6 & & & I & I & I & I & I \\
\hline Trident & & $\mathrm{T}$ & $\mathrm{T}$ & $\mathrm{T}$ & D & & \\
\hline Tender & I & I & I & I & D & & \\
\hline
\end{tabular}

for the remaining five days are similar. Table 3 summarizes the berth shifts that occur in Figure 4. Other than the arrival and departure of submarines, the plan requires only three berth shifts.

To demonstrate the viability of this model, a submarine berthing problem for a typical peak period at San Diego has also been solved. In this problem, a more challenging planning horizon of 14 days is used. The problem contains 10 SSN637's, 10 SSN688's and one Trident. Based on these inputs, GAMS generates 4,380 binary variables, 5,097 continuous variables, and 5,329 constraints in $7 \mathrm{~s}$. Then, CPLEX needs 10 min to obtain a solution within $9 \%$ of optimality. Finally, it takes GAMS another second to generate the output. Because submarines often have to change their service requests and the benefits and penalty terms are somewhat arbitrary, a solution within $10 \%$ of optimality is quite acceptable. However, to experiment further, CPLEX produces a solution within $2 \%$ of optimality in about 24 min when a smaller integrality tolerance ( $5 \%$ of optimality) for solution quality is used. These solution times are acceptable for decision support. The choice of $\mathrm{BN}_{s p b n t}$ and 


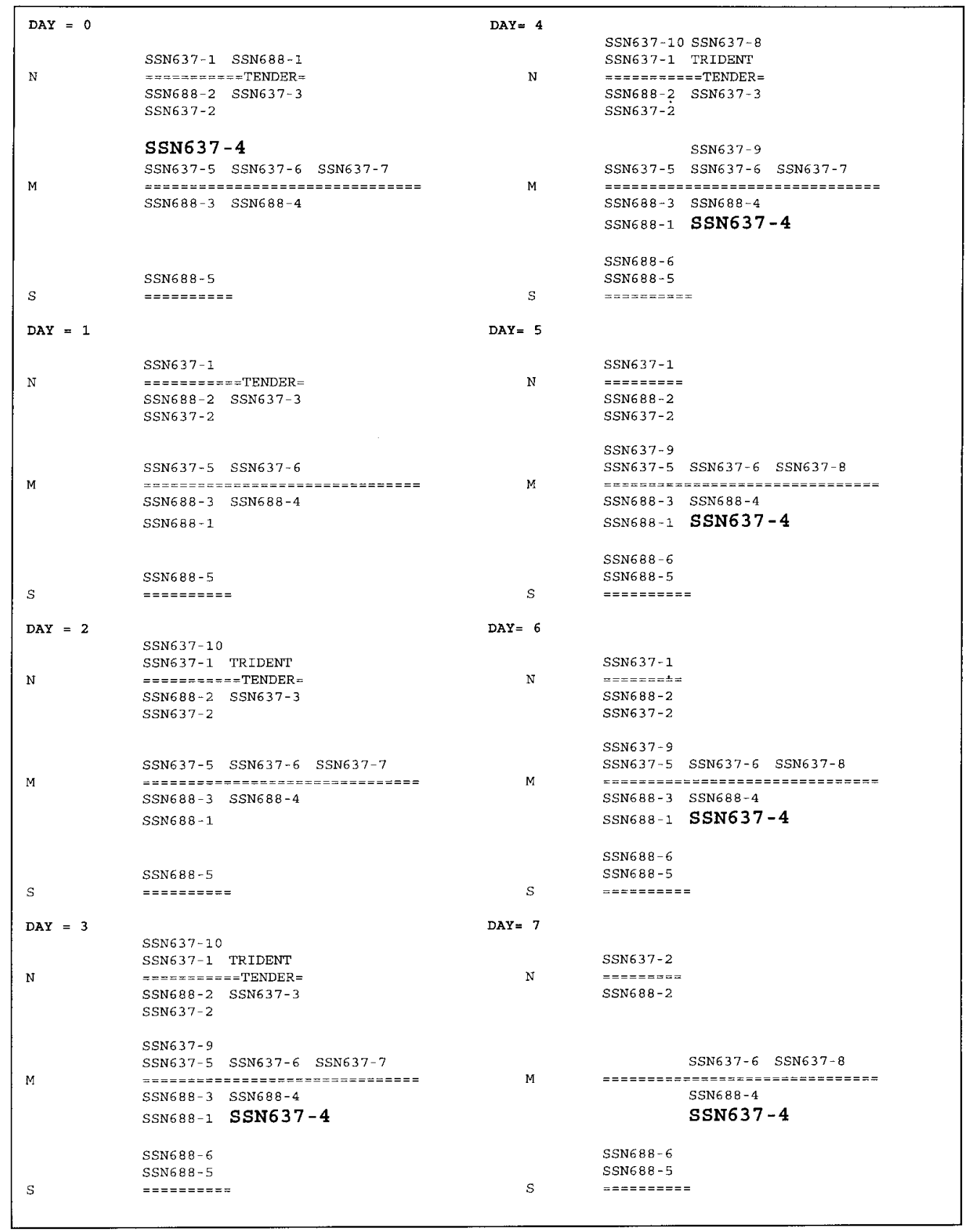

Figure 4. Optimal submarine berthing plan. On Day 0, SSN637-4 is in port at the middle pier, first berth, nesting position 2. It leaves Naval Submarine Station, San Diego, on Day 1 and returns again on Day 3. SSN637-4 needs a weapon loading berth only on Day 6, but is berthed from Day 3 to Day 7 at the south side of the middle pier, second berth, nesting position 2, to avoid berth shifting. 
Table 3. Berth shifts in the optimal berthing plan. Letters A and D, respectively, indicate the arrival and departure of submarines. Shaded cells indicate berth shifts. SSN637-4 departs on Day 1, returns on Day 3, and requires no shifting while in port.

\begin{tabular}{|c|c|c|c|c|c|c|c|}
\hline & D1 & D2 & D3 & D4 & D5 & D6 & D7 \\
\hline SSN637-1 & & & & & & & D \\
\hline \multicolumn{8}{|l|}{ SSN637-2 } \\
\hline SSN637-3 & & & & & D & & \\
\hline SSN637-4 & D & & A & & & & \\
\hline SSN637-5 & & & & & & & D \\
\hline \multicolumn{8}{|l|}{ SSN637-6 } \\
\hline SSN637-7 & D & A & & & D & & \\
\hline SSN637-8 & & & & A & & & \\
\hline SSN637-9 & & & A & & & & D \\
\hline SSN637-10 & & A & & & D & & \\
\hline SSN688-1 & & & & & & & D \\
\hline \multicolumn{8}{|l|}{ SSN688-2 } \\
\hline SSN688-3 & & & & & & & $\mathrm{D}$ \\
\hline \multicolumn{8}{|l|}{ SSN688-4 } \\
\hline \multicolumn{8}{|l|}{ SSN688-5 } \\
\hline SSN688-6 & & & A & & & & \\
\hline Trident & & A & & & D & & \\
\hline
\end{tabular}

the initial submarine positions play an important role in searching for a good solution to the problem - an intrinsically combinatorial problem. Values for $\mathrm{BN}_{s p b n t}$ that discriminate desirable berthing assignments from undesirable ones help in guiding branch-and-bound enumeration to a good solution more quickly. Our values for $\mathrm{BN}_{s p b n t}$ favor berthing closer to shore, piers, or the tender, when it is in port. Brown, Lawphongpanich, and Thurman [4] also time-discount their benefit values to further discriminate near-term berthings from those for the distant future. Initial submarine positions additionally focus the enumeration to those solutions with small deviation from the initial positions, for large deviations would result in large penalties in the objective function.

\section{DEALING WITH CHANGES: A PERSISTENCE INCENTIVE}

Changes are often necessary after a berthing plan has been approved. Changed service requests, delays, and early arrival of inbound vessels are routine events and they require frequent revisions to approved plans. However, these revisions are disruptive and may even induce frustration with and distrust of the planning process. 
In optimization, dealing with changes often implies performing sensitivity analysis and, if necessary, resolving the problem by modifying input to reflect, for example, the changed service requests. Although this would accomplish our initial objectives, for example, minimizing berth shifts, small modifications in input are often amplified into wholesale revisions to the solution prior to the change. One obvious reason for this behavior is that simply resolving the problem with changed input does not take into account the prior solution. Thus, the formulation in Section 3 must account for revisions to the approved plan along with berth shifts, request failures, and berthing benefits.

Let $A_{s p b n t}$ and $X_{s p b n t}$ denote the approved and subsequently revised plans, respectively. By definition, $A_{s p b n t}$ and $X_{s p b n t}$ must be 0 or 1 and satisfy constraints (1) in Section 3. One method of counting the number of revisions is to assess the Hamming distance [8] separating $A$ and $X$ :

$$
\sum_{(s, t)} \sum_{(p, b, n)}\left(1-A_{s p b n t}\right) X_{s p b n t}
$$

When there is no revision in the berthing plan for submarine $s$ on day $t, A_{s p b n t}=X_{s p b n t}$ for all $(p, b, n)$ and the inner summation reduces to zero, indicating no revision to the approved plan. However, when there is a revision, for example, submarine $s$ on day $t$ is located at $\left(p^{\prime \prime}, b^{\prime \prime}, n^{\prime \prime}\right)$ instead of the approved location $\left(p^{\prime}, b^{\prime}, n^{\prime}\right)$, then $A_{s p^{\prime} b^{\prime} n^{\prime} t}=1, A_{s p^{\prime \prime} b^{\prime \prime} n^{\prime \prime} t}=0$, $X_{s p^{\prime} b^{\prime} n^{\prime} t}=0, X_{s p^{\prime \prime} b^{\prime \prime} n^{\prime \prime} t}=1$, and $A_{s p b n t}=X_{s p b n t}=0$ for $(p, b, n) \neq\left(p^{\prime}, b^{\prime}, n^{\prime}\right)$ or $\left(p^{\prime \prime}, b^{\prime \prime}, n^{\prime \prime}\right)$. In this case, $\left(1-A_{s p^{\prime \prime} b^{\prime \prime} n^{\prime \prime} t}\right) X_{s p^{\prime \prime} b^{\prime \prime} n^{\prime \prime} t}$ is the only term in the inner summation that equals 1 , indicating that there is one revision in the approved plan for submarine $s$ on day $t$.

Although many variations of the above expression exist, the following constraint concisely illustrates a simple approach for restricting the number of revisions:

$$
\sum_{(s, t)} \sum_{(p, b, n)} \mathrm{PN}_{s p b n t}\left(1-A_{s p b n t}\right) X_{s p b n t} \leq K
$$

where $\mathrm{PN}_{s p b n t}\left(1-A_{s p b n t}\right)$ is the penalty for moving submarine $s$ to location $(p, b, n)$ on day $t$ and $K$ is the maximum limit for this penalty. To avoid increasing the size of the already large problem, constraint (12) is treated as an aspiration indirectly in the objective function via Lagrangian relaxation. In the following modified objective function, a penalty $\alpha$ is assessed for every unit violation of constraint (12). Note that the constant term $\alpha K$ does not affect the maximization and can be eliminated:

$$
\begin{aligned}
\operatorname{Max} & \sum_{(s, t)} \sum_{(p, b, n)} \mathrm{BN}_{s p b n t} X_{s p b n t}-\sum_{(q, s, t)} \mathrm{QP}_{q} F_{q s t}-\mathrm{SP} \sum_{(p, b, n, t)} Z_{p b n t} \\
& -\alpha \sum_{(s, t)} \sum_{(p, b, n)} \mathrm{PN}_{s p b n t}\left(1-A_{s p b n t}\right) X_{s p b n t} .
\end{aligned}
$$

When $\mathrm{PN}_{s p b n t}=\mathrm{BN}_{s p b n t}$ for all spbnt and $\alpha \in(0,1)$, the objective function becomes

$\operatorname{Max} \sum_{(s, t)} \sum_{(p, b, n)}\left[(1-\alpha) \mathrm{BN}_{s p b n t}+\alpha \mathrm{BN}_{s p b n t} A_{s p b n t}\right] X_{s p b n t}-\sum_{(q, s, t)} \mathrm{QP}_{q} F_{q s t}-\mathrm{SP} \sum_{(p, b, n, t)} Z_{p b n t}$.

In this case, the first summation has a meaningful interpretation. It assigns, as a persistence 
Table 4. Changes of service requests. Shaded cells have been changed. I/P indicates that the original simple IN-PORT request is changed to a pierside request. So, SSN637-4 now needs pierside berthing on Days 5 and 7. O/I indicates that the tender is in port one extra day, Day 5.

\begin{tabular}{|l|c|c|c|c|c|c|c|}
\hline & D1 & D2 & D3 & D4 & D5 & D6 & D7 \\
\hline SSN637-2 & I & I & I & I/P & I/P & I/P & P \\
\hline SSN637-4 & & & I & I & I/P & W & I/P \\
\hline Tender & $\mathrm{I}$ & $\mathrm{I}$ & $\mathrm{I}$ & $\mathrm{I}$ & $\mathrm{O} / \mathrm{I}$ & & \\
\hline
\end{tabular}

incentive (see, e.g., [2]), a full benefit if there is no adjustment for submarine $s$ on day $t$; that is, $X_{s p b n t}=A_{s p b n t}$. Otherwise, submarine $s$ only receives a fraction of this benefit.

There are advantages to this approach. First, the original and modified, persistent problem have the same size and structure. Solution techniques that work well for the original also work well for the persistent modification. In our experience, the persistent problem is much easier to solve. Second, if no change is required, the original and modified problems have the same optimal objective value. This is useful in setting tolerances for guiding the integer enumeration. Finally, choosing $\alpha$ in the $(0,1)$ interval maintains the effectiveness of the berth shift penalty QP. Otherwise, the value of QP must be adjusted to avoid too many berth shifts when large $\alpha$ is used.

To illustrate the approach, let the berthing plan in Figure 4 be the approved plan. Table 4 displays changes to the original service requests in Table 2. In addition to the pierside berthing on Day 7, SSN637-2 now requires a pierside berth on Days 4, 5, and 6 as well. Similarly, SSN637-4 requires a pierside berth on Days 5 and 7. The tender also stays on at the base one extra day, Day 5. For comparison, two submarine berthing plans are produced for the new service requests, one with no incentive term for persistence and one with the incentive term in which $\alpha$ is set at 0.3 . Tables 5 and 6 show revisions to the original approved berthing plan with the use of these two approaches. They show that the incentive term in the modified objective function reduces the number of revisions by $75 \%$ : from 51 to 13. To achieve this level of persistence, some submarines may have to forego more desirable berthing positions and more submarines may have to be shifted. For this example, the benefit of berthing submarines according to the plan without the persistence incentive is 245 , which is approximately $9 \%$ better than the 223 with incentive. Comparing shaded cells in Tables 5 and 6 also reveals that the incentive term allows an additional berth shift to obtain a more persistent solution. Observe that two of the six berth shifts in the persistent solution (Table 6) are the same as in the approved plan (Table 3), whereas none in Table 5 is the same. More important, the persistent solution exhibits revisions that make sense: The revisions principally move submarines with changed requests, or submarines displaced by such.

The above choice for $\alpha$ is empirical. If the chosen value of $\alpha$ produces an unacceptable number of revisions, then larger values should be used. However, large $\alpha$, that is, $\alpha \gg 1$, decreases the effectiveness of berth shift penalty, QP, and may allow too many berth shifts to occur in the revised plan.

\section{CONCLUSIONS}

Time and resource management are always important in naval operations, and intelligent berth scheduling is mandatory to help maintain the readiness of the fleet. With the number 
Table 5. Berth plan revisions from changed service requests without persistence incentive. $\Delta$ represents a berth assignment for the revised plan which is different from the prior approved berthing plan. Shaded cells indicate berth shifts other than arrivals and departures. There are many revisions, and they seem arbitrary and unintuitive. This is not surprising, considering that the model is solved in ignorance of its own prior advice.

\begin{tabular}{|l|c|c|c|c|c|c|c|}
\hline & D1 & D2 & D3 & D4 & D5 & D6 & D7 \\
\hline SSN637-1 & $\Delta$ & $\Delta$ & $\Delta$ & $\Delta$ & $\Delta$ & $\Delta$ & \\
\hline SSN637-2 & & $\Delta$ & $\Delta$ & $\Delta$ & $\Delta$ & $\Delta$ & $\Delta$ \\
\hline SSN637-3 & & & & & & & \\
\hline SSN637-4 & & & $\Delta$ & $\Delta$ & $\Delta$ & $\Delta$ & $\Delta$ \\
\hline SSN637-5 & & & & & & & \\
\hline SSN637-6 & & & & & & & \\
\hline SSN637-7 & & & & & & & \\
\hline SSN637-8 & & & & $\Delta$ & $\Delta$ & $\Delta$ & $\Delta$ \\
\hline SSN637-9 & & & $\Delta$ & $\Delta$ & $\Delta$ & $\Delta$ & \\
\hline SSN637-10 & & $\Delta$ & $\Delta$ & $\Delta$ & & & \\
\hline SSN688-1 & $\Delta$ & $\Delta$ & $\Delta$ & $\Delta$ & $\Delta$ & $\Delta$ & \\
\hline SSN688-2 & & & & & & & \\
\hline SSN688-3 & & $\Delta$ & $\Delta$ & $\Delta$ & $\Delta$ & $\Delta$ & \\
\hline SSN688-4 & $\Delta$ & $\Delta$ & $\Delta$ & $\Delta$ & $\Delta$ & $\Delta$ & $\Delta$ \\
\hline SSN688-5 & & & & & & & \\
\hline SSN688-6 & & & $\Delta$ & $\Delta$ & $\Delta$ & $\Delta$ & $\Delta$ \\
\hline Trident & & & & & & & \\
\hline
\end{tabular}

of details to consider, human schedulers tend to generate unnecessary berth shifts. An automatic, optimization-based decision support system that prevents unnecessary berth shifts will clearly contribute to the readiness of the fleet. This article presents two optimization models for submarine berthing. The first model is for generating a berthing plan and the other is an extension to deal gently with changes once the plan is approved.

For the first model, the submarine berthing problem is formulated as a mixed-integer program that assigns submarines to berthing locations while they are in port. There are two objectives for the assignment: One is to maximize the benefits of berth allocations, and the other is to minimize the penalties due to berth shifts and unfulfilled requested services. These two objectives are combined into a single objective function. The model is implemented in GAMS and tested with data from Naval Submarine Base, San Diego, California. The model is applicable to any submarine base (see, e.g., Naval Submarine Base, Charleston, South Carolina [13]).

An extension of the model reduces the number of revisions to an approved plan via a 
Table 6. Berth plan revisions with persistence incentive. $\delta$ represents a berth assignment in the revised persistent plan which is different from the prior approved berthing plan. Shaded cells indicate berth shifts other than arrivals and departures. The persistence incentive reduces the number of revisions. Revisions are more obviously necessitated by the changed service requests in Table 4. During the last 4 days of the revised plan, SSN637-2 is now assigned to a pierside location previously occupied by SSN637-6 in the approved plan. Similarly, SSN637-4 is assigned to pierside location previously approved for SSN637-1 during the last 3 days.

\begin{tabular}{|c|c|c|c|c|c|c|c|}
\hline & D1 & D2 & D3 & D4 & D5 & D6 & D7 \\
\hline SSN637-1 & & & & & $\delta$ & $\delta \varrho$ & \\
\hline SSN637-2 & & & & $\delta$ & $\delta$ & $\delta \varrho$ & $\delta$ \\
\hline SSN637-3 & & & & & & & \\
\hline SSN637-4 & & & & & $\delta$ & $\delta \varrho$ & $\delta$ \\
\hline SSN637-5 & & & & & & & \\
\hline SSN637-6 & & & & $\delta$ & $\delta$ & $\delta$ & $\delta$ \\
\hline SSN637-7 & & & & & & & \\
\hline SSN637-8 & & & & & & & \\
\hline SSN637-9 & & & & & & & \\
\hline SSN637-10 & & & & & & & \\
\hline SSN688-1 & & & & & & & \\
\hline SSN688-2 & & & & & & & \\
\hline SSN688-3 & & & & & & & \\
\hline SSN688-4 & & & & & & & \\
\hline SSN688-5 & & & & & & & \\
\hline SSN688-6 & & & & & & & \\
\hline Trident & & & & & & & \\
\hline
\end{tabular}

persistence incentive term added to the objective function. In a sample problem, the incentive decreases the number of revisions by $75 \%$. Minimizing revisions to an approved plan reduces disruption and, in turn, promotes acceptance of the planning process.

\section{APPENDIX}

\section{Naval Submarine Base, San Diego: Berthing Guidelines}

- SSN-688 (Los Angeles) class submarines should not berth on the north side of middle pier.

- A pierside berth should be assigned to a submarine returning from or going on a deployment.

- Submarines should receive a pierside berth for pre-overseas movement (POM) loading, vertical launch system (VLS) missile loads, or weapons (other than VLS) loads. 
- A pierside or tenderside berth should be assigned for oxygen loads.

- Weapons loads are not allowed on south pier or north side inner middle pier due to explosive handling arcs.

- Upkeeps should take place as close to the tender as possible, preferably alongside the tender or on the same pier.

- Screw replacement should occur at a pierside berth.

- Hull cleaning should occur with no other submarines alongside.

- Major shipyard work should take place on south pier.

- Towed array removal or installation should take place pierside.

- A SPRUCE (submarine preservation period) should be conducted at south pier.

- Submarines receiving special additional shore power cannot be nested outboard because of shore power limitations.

- Special nuclear testing should be accomplished at south pier or tenderside.

\section{REFERENCES}

[1] Brooke, A., Kendrick, D., and Meeraus, A., GAMS: A User's Guide, Scientific Press, South San Francisco, 1992.

[2] Brown, G., Dell, R., and Farmer, R., "Scheduling Coast Guard District Cutters," Interfaces, 26, 59-72 (1996).

[3] Brown, G., Dell, R., and Wood, R., “'Optimization and Persistence," Interfaces, (to appear).

[4] Brown, G., Lawphongpanich, S., and Thurman, K., "Optimizing Ship Berthing," Naval Research Logistics, 41, 1-15 (1994).

[5] COMNAVSUBASE, Naval Submarine Base San Diego, Letter 11010: Serial 09/0097 to Commander, Submarine Force, U.S. Pacific Fleet, Subject: Submarine Berthing Capability, January 1992.

[6] Cormican, K., “Optimal Submarine Berthing at San Diego, CA,” Class Project for OA3201: Linear Programming, Department of Operations Research, Naval Postgraduate School, Monterey, CA, December, 1993.

[7] CPLEX Optimization, Inc., CPLEX 3.0, Incline Village, NV, 1994.

[8] Hamming, R., Coding and Information Theory (2nd ed.), Prentice-Hall, Englewood Cliffs, NJ, 1986.

[9] Microsoft Corp., Microsoft Excel 4.0: User's Guide 1, Redmond, WA, 1992.

[10] Microsoft Corp., Microsoft Excel 4.0: User's Guide 2, Redmond, WA, 1992.

[11] Nicholas, T., and Rossi, R. (Eds.), Military Cost Handbook, Data Search Associates, Fountain Valley, CA, 1994.

[12] Thurman, K., "Optimal Ship Berthing Plans," M.S. thesis, Department of Operations Research, Naval Postgraduate School, Monterey, CA, March 1989.

[13] Widdis, D., "Optimizing Submarine Berthing at Charleston, SC," Class Project for OA3201: Linear Programming, Department of Operations Research, Naval Postgraduate School, Monterey, CA, December 1993. 